\title{
DESULPHURIZATION OF LIQUID FUELS BY SELECTIVE ADSORPTION THROUGH MINERAL CLAYS AS ADSORBENTS
}

\author{
M. SHAKIRULLAH, W. AHMAD, I. AHMAD, M. ISHAQ AND M. I. KHAN
}

Institute of Chemical Sciences, University of Peshawar, 25120, KPK Pakistan

(Received: December 13, 2011 - Accepted: July 23, 2012)

\begin{abstract}
Different clays collected from local sources, including Kaolinite, Montmorollinte, Palygorskite and Vermiculite have been utilized for the selective adsorption of sulphur compounds prevailing in petroleum products i.e. crude oil, kerosene and diesel oil. The desulphurization activity of the clay was compared with the charcoal, ion exchange resins and with each other. Desulphurization was performed in batch operation at different time intervals i.e 1,3 and 6 hrs at $40{ }^{\circ} \mathrm{C}$ temperature. Out of different adsorbents used, Kaoilinte exhibited the maximum desulphurization yield of $60 \%, 76 \%$ and $64 \%$ at 6 hrs adsorption incase of crude oil, kerosene and diesel oil respectively. All the mineral clays adsorbents were characterized by surface area, SEM and EDX analysis. The FT-IR study of the desulphurized fractions revealed that mostly high molecular weight thioles and thiophenic compounds were depleted during adsorption process.
\end{abstract}

Key Words: Adsorptive desulphurization, Mineral clays, Kaolinite, Sulphur compounds, Liquid fuels.

\section{INTRODUCTION}

Sulphur and its organic homologues are undesirable in the liquid fuels due to the cause of environmental pollution and hindrance in a variety of refining processes e.g. catalyst poisoning during catalytic hydrotreatment, resistance to octane boosting and corrosion of the equipments [1-3]. Desulphurization has therefore become an unavoidable process for the refiners. Currently the Hydrodesulphurization (HDS) process is the sole tool employed in the refineries all over the world to cater this problem. However HDS process is inconvenient due to its uneconomic requirements like high temperature and pressure, Hydrogen gas and costly catalysts, also its efficiency is low for removal of refractory sulphur compounds [4]. It is therefore needed to develop more efficient and affordable processes for desulphurization of liquid fuels.

Recently the researchers have developed several new processes for desulphurization which include biodesulphurization [5,6], desulphurization by precipitation $[7,8]$, oxidative desulphurization [9-11] and adsorptive desulphurization [12]. Out of these the adsorptive desulphurization is gaining more popularity due to producing promising results while operating at ambient pressure and temperature. The various adsorbents so far employed for desulphurization of liquid fuels include modified composite oxides [13], activated carbon [14], mesopourous molecular sieves e.g. SBA-15, MCM-41 and Fujasite [15-17] etc and microporous Zeolites e.g. 5-A, 13-X, ZSM-5 and Y-Zeolite, [18-20]. A recent advancement in this field employs desulphurization through $\pi$-complexation with cations exchanged Zeolites like $\mathrm{Ce}-\mathrm{Y}, \mathrm{Ag}-\mathrm{Y}, \mathrm{Cu}-$ $\mathrm{Y}, \mathrm{Ni}-\mathrm{Y}$ etc. which is superior to ordinary adsorption due to its high efficiency as the $\pi$-complexation bond is stronger than the Vander Walls interactions [21, $22]$. Besides there is another group of adsorbents, i.e. mineral clays, which is enjoying popularity in various industries for purification purposes, due to their complex crystalline structure. The same can also be used for adsorptive desulphurization of the liquid fuels.

In the present work four different types of locally available mineral clays or natural Zeolites e.g. Kaolinte, Montmorollinite, Palygorskite and Vermiculite, activated carbon and ion exchange resin have been employed for selective adsorption of organic Sulphur compounds from Jhal Magsi petroleum crude and its two distillates fractions i.e. Kerosene and diesel.

\section{EXPERIMENTAL}

\subsection{Samples Collection:}

Sample of crude petroleum was collected from Jhal Magsi oil field located in the Baolchistan province, Pakistan. The crude oil was subsequently distilled using Engler distillation apparatus to obtain different distillates fractions, including gasoline (b.pt $30-180^{\circ} \mathrm{C}$ ), kerosene (b.pt $180-250{ }^{\circ} \mathrm{C}$ ), diesel (b.pt $250-320^{\circ} \mathrm{C}$ ) and heavy residue (b.pt $>320^{\circ} \mathrm{C}$ ). Out of these only crude oil, kerosene and diesel oil samples were used for desulphurization study. The fractions obtained were analyzed for their various physicochemical properties, employing the standard procedures of ASTM an API, as described below.

The clay samples used in the study included Montmorollinite, Kaolinite, vermiculite and palygorskite, which were collected from local sources; Kaolinite was collected from china clay processing factory, Swat. Montmorollinite and Vermiculite was brought from Soil Sciences Laboratory, Pakistan Council of Industrial Research (PCSIR), Peshawar, while Palygorskite clay was collected from Lund Khwar, Mardan. Before the clays were used for adsorption, these were modified with acids in order to remove the foreign materials and increase adsorption capacity.

\subsection{Acid treatment clay adsorbents}

$50 \mathrm{gm}$ of the clay sample was taken in the round bottom flask and $250 \mathrm{ml}$ of the acid solution $(0.1 \mathrm{~N} \mathrm{HCl})$ was added to it. The sample was refluxed with constant stirring for 2 hours. The clay slurry was then filtered through Buchner funnel and washed several times with deionized water. The sample was dried in the oven at $120^{\circ} \mathrm{C}$ overnight. The dried clay was then grinded to fine powder and then screened through 120 micron mesh sieve. The powdered clay samples were then activated by calcination at $550^{\circ} \mathrm{C}$ for 4 hours in the Muffle furnace. The samples was cooled in desiccator and stored in closed containers.

\subsection{Desulphurization of the petroleum fractions.}

Desulphurization experiments were carried out in batch operation. In typical procedure, $20 \mathrm{ml}$ of the sample was taken in the Erlenmeyer flask and $1 \mathrm{~g}$ of clay/adsorbent was added to it. The samples ware stirred with magnetic stirrers for desired period of time and at specific at room temperature. Adsorption was investigated at different duration of time i.e. $1 \mathrm{hr}$, $3 \mathrm{hrs}$ and 6 hrs. The sample was filtered and analyzed for sulphur contents.

\subsection{Product analysis:}

Prior to use for desulphurization studies, the mineral clays were characterized by various analytical methods to know its surface area, morphology and mineralogical composition. The surface area of the clay samples was determined with surface area analyzer (Quantachrome Nova station A). The morphological and compositional characterization of mineral clays was carried out with the help of Scanning Electron Microscopy (SEM) and Energy Dispersive X-ray analysis. SEM examination of the clay samples was carried out by scanning electron microscope Model No. JEOL-Jsm-5910, Japan. The mineralogical composition of the clays was determined by Energy Dispersive X-rays Spectrometer (EDX Model Inea 200, UK Company Oxford).

Total Sulphur in virgin and treated oil samples was analyzed through Leco SC-144DR carbon sulphur analyzer. The nature of the sulphur compounds in the virgin and treated hydrocarbons was determined by FT-IR spectrophotometer Model No. FT-IR-8201 ICP (Shimadzu, Japan), using KBr discs. The analysis was done using special software HYPER IR (Shimadzu). The range of the instrument was $400-4000 \mathrm{~cm}^{-1}$ and the scan time was 10 seconds.

\section{RESULTS AND DISCUSSION}

\subsection{Physicochemical characterizations of the fuels}

The petroleum fractions used in the study i.e. kerosene, diesel and crude oil were characterized by determining some of its general physicochemical properties of the gasoline and kerosene fractions were carried out, employing standard methods of the ASTM and IP. The results are displayed in the Table-1. 
Table-1. Physicochemical characterization of kerosene, diesel and crude oil.

\begin{tabular}{|c|c|c|c|c|}
\hline Characteristics & Method used & Kerosene & Diesel & Crude oil \\
\hline Specific gravity & IP-160/87 & 0.7902 & 0.8360 & 0.8022 \\
\hline API gravity & - & 45.81 & 37.75 & 44.88 \\
\hline $\begin{array}{c}\text { Kinematic } \\
\text { viscosity cSt @ } \\
100 \mathrm{~F}\end{array}$ & $\begin{array}{c}\text { ASTM-D } \\
455-04\end{array}$ & 2.217 & 3.814 & 1.525 \\
\hline $\begin{array}{c}\text { Aniline point } \\
\left({ }^{\circ} \mathrm{C}\right)\end{array}$ & $\begin{array}{c}\text { ASTM-D } \\
611-04\end{array}$ & 60 & 66 & 71 \\
\hline Flash point $\left({ }^{\circ} \mathrm{C}\right)$ & IP-34/87 & 46.3 & 52.1 & 42.66 \\
\hline $\begin{array}{c}\text { Ash contents } \\
(\mathrm{wt} \%)\end{array}$ & $\begin{array}{c}\text { ASTM-D } \\
482-03\end{array}$ & 0.065 & 0.085 & 0.119 \\
\hline $\begin{array}{c}\text { Conradson } \\
\text { carbon residue } \\
(\mathrm{wt} \%)\end{array}$ & IP-13/92 & 0.18 & 0.21 & 1.15 \\
\hline $\begin{array}{c}\text { Total sulphur } \\
(\mathrm{wt} \%)\end{array}$ & $\begin{array}{c}\text { ASTM D } \\
129-83\end{array}$ & 1.184 & 1.564 & 1.174 \\
\hline
\end{tabular}

3.2. Characterization of clay samples:

The mineral clays were characterized by various analytical methods to know its surface area, morphology and mineralogical composition.

3.2.1 Surface area

The surface area of the clay samples was determined by surface area analyzer using BET isotherm under the experimental conditions given in table 2. Results of surface area of different clay samples are displayed in table 3. It is clear from the data in the table that high surface area is exhibited by vermiculite clay, that of $34.75 \mathrm{~m}^{2} / \mathrm{g}$, followed by kaolinite having surface area of $30.08 \mathrm{~m}^{2} / \mathrm{g}$, montmorollinite showing $20.57 \mathrm{~m}^{2} / \mathrm{g}$ and palygorskite showing surface area of $14.66 \mathrm{~m}^{2} / \mathrm{g}$. in general adsorbents with high surface area are supposed to bear high adsorption efficiency.

Table 2. Conditions used for determination of surface area of the clay samples.

\begin{tabular}{|l|c|c|c|}
\hline Parameters & Conditions & Parameters & Conditions \\
\hline Thermal Transpiration & On & Adsorbate & Nitrogen \\
\hline Eff. Mol. Dia. (D) & $3.5400 \AA$ & $\begin{array}{c}\text { Molecular } \\
\text { Weight }\end{array}$ & \begin{tabular}{c}
$28.013 \mathrm{~g} / \mathrm{mol}$ \\
\hline Eff. Cell Stem Dia. (d)
\end{tabular} \\
\hline Po Override & $760 \mathrm{~mm} \mathrm{Hg}$ & Density & $0.808 \mathrm{~g} / \mathrm{cc}$ \\
\hline Temperature & $77.350 \mathrm{~K}$ & Sample Weight & $1.000 \mathrm{~g}$ \\
\hline Outgas Temp & $100^{\circ} \mathrm{C}$ & Outgas Time & $1 \mathrm{hr}$ \\
\hline Analysis Time & $6.5 \mathrm{~min}$ & Bath Temp. & $77.4 \mathrm{~K}$ \\
\hline
\end{tabular}

Table 3. Surface area of the clay samples.

\begin{tabular}{|c|c|c|}
\hline S. No & Clay Sample & Surface area $\left(\mathbf{m}^{2} / \mathbf{g}\right)$ \\
\hline 1. & Palygorskite & 14.66 \\
\hline 2. & Kaolinite & 30.08 \\
\hline 3. & Montmorollinite & 20.57 \\
\hline 4. & Vermiculite & 34.75 \\
\hline
\end{tabular}

\subsubsection{EDX analysis of the mineral clays}

The EDX analysis of the mineral clays was carried out in order to know their mineralogical nature and chemical composition. The EDX profile (Fig-4) of montmorolinite or bentonite $\left((\mathrm{Na}, \mathrm{Ca})_{0.33}(\mathrm{Al}, \mathrm{Mg})_{2} \mathrm{Si}_{4} \mathrm{O}_{10}(\mathrm{OH}) . \mathrm{n} \mathrm{H}_{2} \mathrm{O}\right)$ which belongs to subgroup Smectite shows that percentage of $\mathrm{Al}$ and $\mathrm{Si}$ in the sample is 9.26 and $26.6 \%$, respectively. Whereas the percentages of other metals like $\mathrm{Fe}, \mathrm{Ca}, \mathrm{K}, \mathrm{Mg}$ and $\mathrm{O}$ is $11.19,2.27,4.78,3.46$ and $42.38 \%$, respectively. The major constituents of the clay are aluminum, silicon, magnesium, iron, oxygen and calcium, which correspond to its chemical formula.

The EDX profile of vermiculite, having chemical formula of $\left(\mathrm{Mg}, \mathrm{Fe}^{+3}\right.$, $\mathrm{Al})_{3}(\mathrm{Al}, \mathrm{Si})_{4} \mathrm{O}_{10}(\mathrm{OH})_{2} .4 \mathrm{H}_{2} \mathrm{O}$, is exhibited in the Fig-5, which shows that the percentage $\mathrm{Al}, \mathrm{Si}, \mathrm{Fe}, \mathrm{K}, \mathrm{Mg}$ and $\mathrm{O}$ in the clay sample is $10.76,28.84$, $8.76,3.44,2.56$ and $45.64 \%$, respectively. Fig- 6 shows the EDX profile of the Kaolinite clay. The chemical formula of the kaolinite clay is $\mathrm{Al}_{2} . \mathrm{Si}_{2} \mathrm{O}_{5}$ $(\mathrm{OH})_{4} \cdot 2 \mathrm{H}_{2} \mathrm{O}$, and is commonly referred as China clay, which belongs to clay group kandite and subgroup kaolinite. The EDX studies revealed that the percentage of the $\mathrm{Al}, \mathrm{Si}$ and $\mathrm{O}$ in the kaolinite sample is 18.28, 27.38 and $54.34 \%$, respectively. Mineral clay palygorskite, having the chemical formula of $(\mathrm{Mg}, \mathrm{Al})_{2} \cdot \mathrm{Si}_{4} \mathrm{O}_{10}(\mathrm{OH}) .4 \mathrm{H}_{2} \mathrm{O}$, belongs to clay group of palygonkite and sub group palygorskite The EDX profile (Fig-7) of the palygorskite shows that the percentage of $\mathrm{Al}, \mathrm{Si}, \mathrm{Mg}$ and $\mathrm{O}$ is $10.75,35.98,2.72$ and $50.55 \%$, respectively.

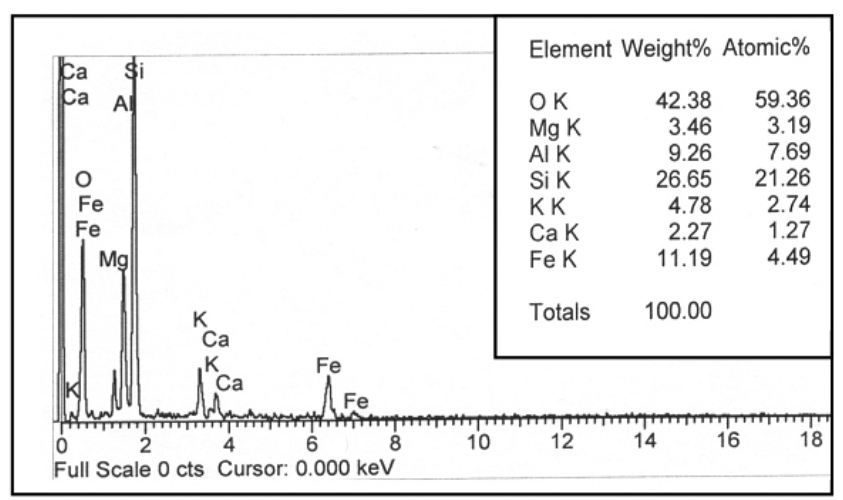

Fig-1.- EDX profile of montmorolinite clay.

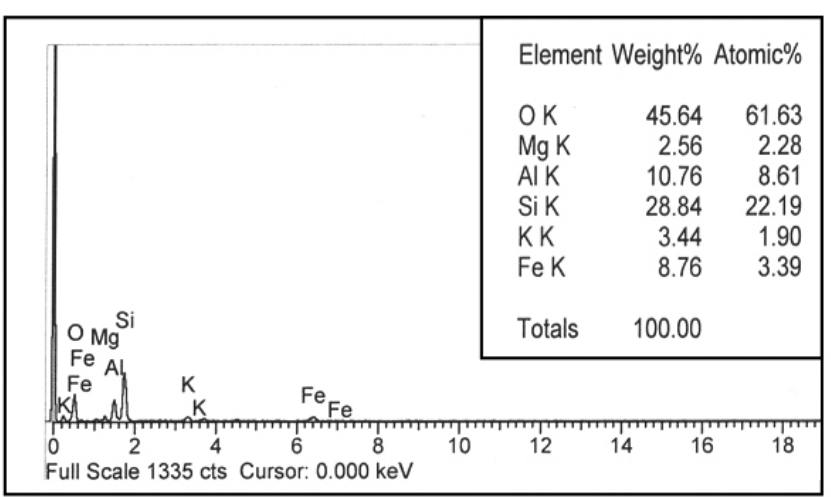

Fig-2.- EDX profile of vermiculite clay.

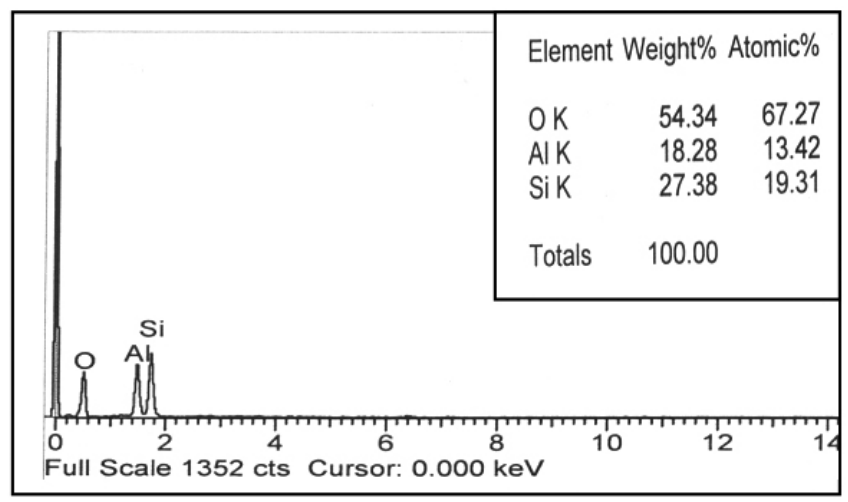

Fig-3.- EDX profile of kaolinite clay. 


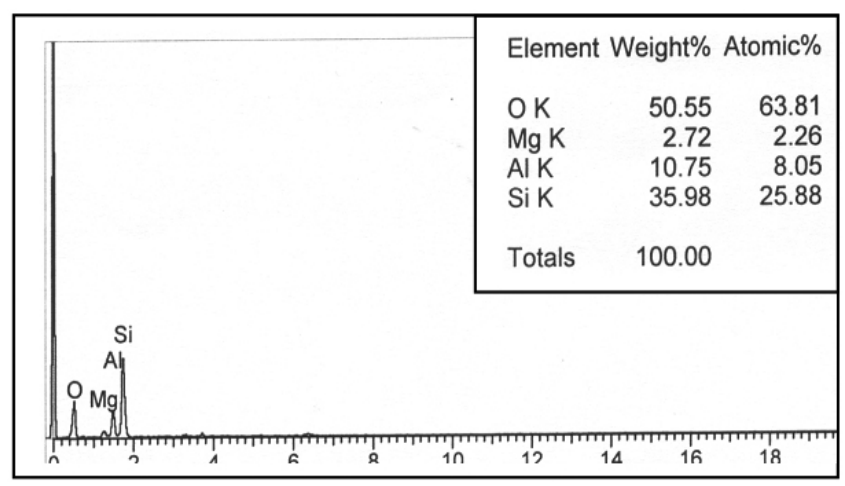

Fig-4.- EDX profile of palygorskite clay.

\subsubsection{SEM analysis of the mineral clays}

In order to examine the surface morphology of the clay adsorbents, scanning electron microscopic analysis of the samples was carried out, SEM images of the clay samples are displayed in Fig. 7-10. SEM micrographs of montmorollinite/bentonite clay (Fig-7.a, b) clearly show the porous and uniform textural surface of the clay mineral. The particles size is relatively small. Major fissures and channels are evident. The layered surface can be seen clearly. The SEM micrographs of vermiculite clay (Fig-8.a,b) indicate major fissures and channels on the surface. Also the layered structure with larger pores can be seen. The surface is mainly comprised of irregularities and plateaus. The textural non-uniformity is evident in both magnification i.e. $5 \mu \mathrm{m}$ and $10 \mu \mathrm{m}$ images.

SEM micrographs of the kaolinte clay (Fig-9.a,b) show clearly that the surface is highly porous due to the small particle size and pore dimensions. The fissures and channels are major, which suggests that surface consists of many layers, and the textural non-uniformity is clearly evident on the surface. These textural characteristics render the clay to bear better adsorption capacity. The SEM micrographs of the palygorskite clay (Fig-10), indicates that the surface of the material is serrated with numerous protrusions. Surface deformities can be seen in the form of channels and fissures. The particle size is larger and the pore dimension is sufficiently larger. The surface is mainly comprised of irregularities and plateaus. No interstices can be seen.

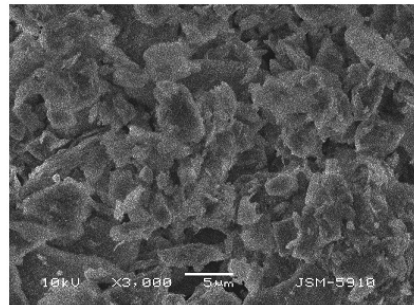

5(a)

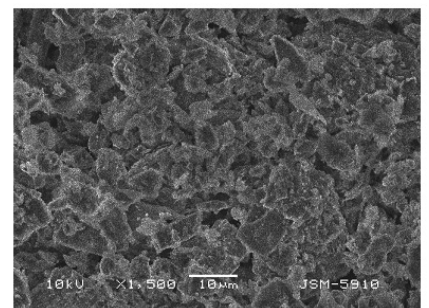

5(b)
Fig-5.- SEM images of montmorollinite/bentonite

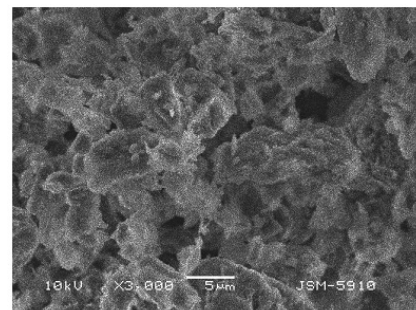

6(a)

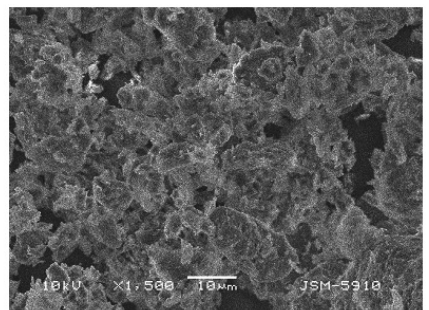

6(b)
Fig-6.- SEM images of vermiculite

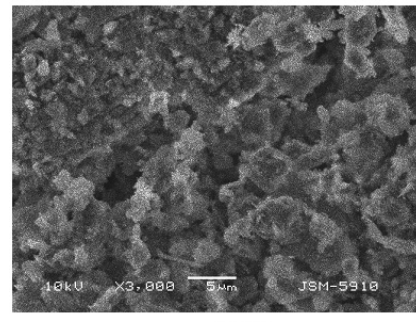

7 (a)

Fig-7.- SEM images of palygonskite

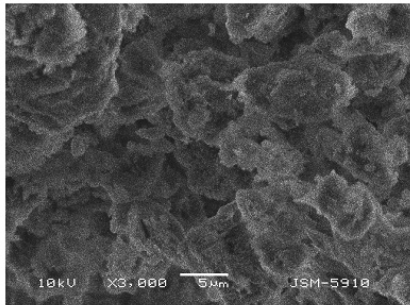

8(a)

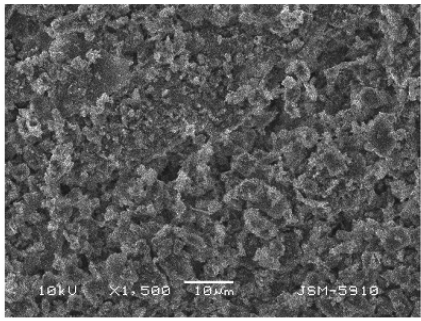

7(b)

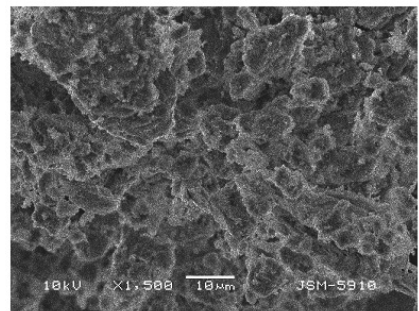

8(b)
Fig-8.- SEM images of kaolinite

(a) $5 \times$ magnification (b) $10 \times$ magnification

\subsection{Desulphurization}

Adsorptive desulphurization of Jhal Magsi Crude oil, kerosene oil and diesel oil was carried out using zeolitic clays (montmorollinite, vermiculite, palygorskite and kaolinite), Charcoal and ion exchange resin as adsorbents for the sulphur compounds at $40{ }^{\circ} \mathrm{C}$ for different time intervals i.e. one hour, three hours and six hours. Tables 4 display the results of total desulphurization carried out by adsorption of Jhal Magsi Crude oil, kerosene oil and diesel oil.

\subsubsection{Jhal Magsi crude oil:}

In case of Jhal Magsi petroleum crude, highest desulphurization efficiency is exhibited by adsorption through kaolinite clay, which have attained desulphurization yield of $60.02 \%$ for six hours adsorption time, while in case of one hour and two hours adsorption time, the desulphurization yields obtained are $51 \%$ and $59 \%$, respectively. Other clays used as adsorbents have relatively poor desulphurization yields. The maximum desulphurization achieved with montmorollinite, vermiculite and palygorskite are $46 \%, 52 \%$ and $42 \%$, respectively after 6 hours reaction time. In case of one hour reaction time, the same adsorbents have attained $29 \%, 36 \%$ and $26 \%$, respectively, whereas in case of three hours adsorption, desulphurization of $33 \%, 43 \%$ and $32 \%$ have been achieved, respectively. Adsorption with charcoal has brought about a maximum desulphurization of $45 \%$ for one hour reaction time, which show a decline with increasing or decreasing adsorption time. For one hour and six hours, the \% depletion in total sulphur brought about by charcoal is $42 \%$ and $39 \%$, respectively. Using ion exchange resins as adsorbent, highest desulphurization achieved is $47 \%$ for six hours adsorption time, while for one hour 34\% and for three hour, $38 \%$ desulphurization is achieved.

As discussed in earlier section, that due to its high surface area and smaller particle size, Kaolinite clay exhibited higher adsorption efficiency for sulphur compounds. Although vermiculite had surface area greater than kaolinite but $\%$ desulphurization yield is lower, which may be attributed to its mineralogical composition and structure. Unlike kaolinite, the alumino-silicate framework is covered by large number of metals, due to which it showed lower adsorption efficiency for sulfur compounds.

\subsubsection{Kerosene oil}

In case of kerosene kaolinite has shown the highest desulphurization activity of $75 \%$ for six hours adsorption time, while for one hour and three hours $66 \%$ and $57 \%$ desulphurization were obtained, respectively. Like kaolinite, the other adsorbents clays have also carried out maximum desulphurization as the adsorption time was extended. Montmorollinite, vermiculite and palygorskite have achieved maximum desulphurization of $44 \%, 44 \%$ and $46 \%$, respectively after six hours adsorption, while for one hour and three hours adsorption time the desulphurization yields are $42 \%, 38 \%$ and $43 \%$, and $28 \%, 34 \%$ and $37 \%$, respectively. In case of using charcoal as adsorbent, the desulphurization yield is higher i.e. $40 \%$, while for one hour and six hours reaction time the yields are low i.e. $30 \%$ and $38 \%$, respectively. In case of exchange resin, the desulphurization yield is highest for six hours reaction time that is $49 \%$, while in case of one hour and three hours the yields are $28 \%$ and $33 \%$ respectively. 


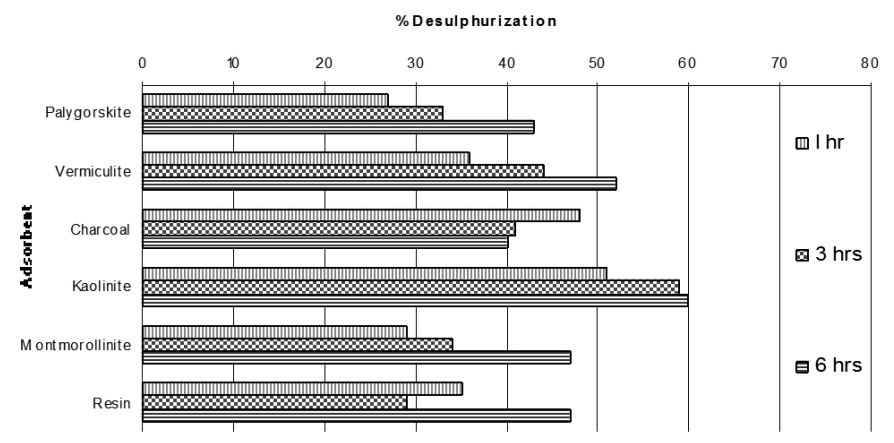

Fig.9.- \% Desulphurization of crude oil by adsorption through different adsorbents at different time intervals.

Table. 4. \% Desulphurization of Jhal Magsi crude oil, kerosene and diesel oil through adsorption as a function of Time.

\begin{tabular}{|c|c|c|c|c|c|c|c|c|c|}
\hline \multirow{3}{*}{ Adsorbents } & \multicolumn{9}{|c|}{ \% Desulphurization* } \\
\hline & \multicolumn{3}{|c|}{ Crude oil } & \multicolumn{3}{|c|}{ Kerosene } & \multicolumn{3}{|c|}{ Diesel } \\
\hline & I hr & $3 \mathrm{hrs}$ & $6 \mathrm{hrs}$ & I hr & $3 \mathrm{hrs}$ & $6 \mathrm{hrs}$ & I hr & $3 \mathrm{hrs}$ & $6 \mathrm{hrs}$ \\
\hline Palygorskite & 27 & 33 & 43 & 37 & 43 & 46 & 40 & 35 & 44 \\
\hline Vermiculite & 36 & 44 & 52 & 34 & 39 & 44 & 17 & 59 & 46 \\
\hline Charcoal & 48 & 41 & 40 & 30 & 36 & 43 & 23 & 43 & 37 \\
\hline Kaolinite & 51 & 59 & 60 & 57 & 67 & 76 & 41 & 56 & 64 \\
\hline Montmorollinite & 29 & 34 & 47 & 28 & 43 & 31 & 33 & 34 & 29 \\
\hline Resin & 35 & 29 & 47 & 28 & 34 & 49 & 25 & 48 & 38 \\
\hline
\end{tabular}

*Sulphur contents in virgin crude oil $1.17 \%$ wt kerosene oil $1.18 \%$ wt and Diesel oil $1.57 \%$ wt.

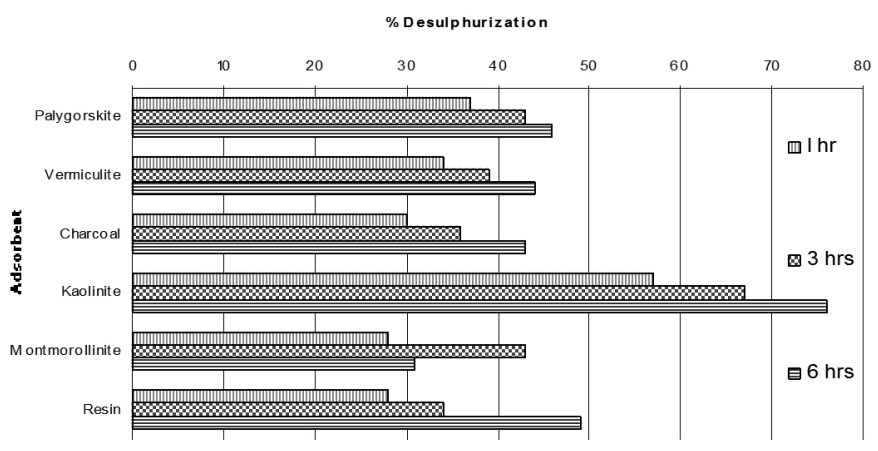

Fig.10.- \% Desulphurization of kerosene by adsorption through different adsorbents at different time intervals.

\subsubsection{Diesel oil}

In diesel oil is, the trend in desulphurization results is similar to that of kerosene. The maximum desulphurization yield obtained is $63 \%$ for six hours reaction time, while the value of desulphurization for one and three hours are considerably low which are $40 \%$ and $55 \%$ respectively. Highest desulphurization values in case of montmorollinite vermiculite and palygorskite are $38 \%, 55 \%$ and $43 \%$, respectively for six hours reaction time. The mentioned adsorbents have attained $42 \%, 46 \%$ and $43 \%$ desulphurization for three hours and $28 \%, 37 \%$ and $39 \%$ desulphurization for one hour adsorption tine. In case of charcoal, the desulphurization yield is poor for one hour i.e. $23 \%$, then maximum for three hours i.e. $42 \%$ and then declined for six hours reaction i.e. $37 \%$. In case of ion exchange resin, the desulphurization yields are $24 \%, 37 \%$ and $48 \%$ for one hour, three hours and six hours reaction times, respectively.

Application of some mineral clay types for adsorptive desulphurization has already been reported elsewhere [23]. In case of clays, adsorption occurs on the upper surface layer, lower basal layers and then on the middle layers as the time extends. In this case, during one hour reaction time, the adsorption may have taken place on the upper and lower basal layers, then in the next three hours, adsorption on the internal layers have been started which has needed more time to complete and reach to maximum in six hours. Out of all clays used, kaolinite showed the maximum desulphurization yield. Vermiculite have also exhibited considerable desulphurization yield in case of crude oil and diesel oil. While in case of montmorollinite and palygorskite, the desulphurization yields are very poor. The highest desulphurization capacity of the kaolinite clay may be attributed to its larger surface area and small porous structure enough to retain sulphur bearing molecules $[17,19]$, as also shown by the surface area analysis of the clay sample discussed in earlier section. Secondly, the mineralogical composition of kaolinite also shows that it consists of simple alumino-silicate frame works, which provide better adsorption capacity. The same reason may also be given in case of vermiculite. The SEM and EDX analysis of kaolinite and vermiculite both support this view. While the larger particle size and the complex mineralogical composition, in which the alumino silicates framework is incorporated by other elements might have reduced their adsorption capacity. The desulphurization yield in case of charcoal as adsorbent was significant in three hours shaking time as compared to one hour. This is attributed due to multi layer adsorption. In the initial state, the poor adsorption was due to monolayer adsorption for the first hour. The multilayer adsorption completed in three hours, resulting in the higher desulphurization yield, while after that, desorption starts leading to decline in the desulphurization yield. Similarly, the low desulphurization yield suggests that the specific ion exchange resin used in the current study have low chemically affinity for sulphur bearing molecules.

As the koalinite clay has been known to exhibit some hydrophobic character $[24,25]$ because of its heterogenous surface, which facilitates the interaction of nonpolar (oil) molecules with the clay particles, and hence leads to selective adsorption of the sulphur bearing organic molecules. However the adsorption of the sulphur containing molecules on the clay surface may be attributed to the interaction with aluminosilcate framework and not because of the attraction between the hydrophobic centers.

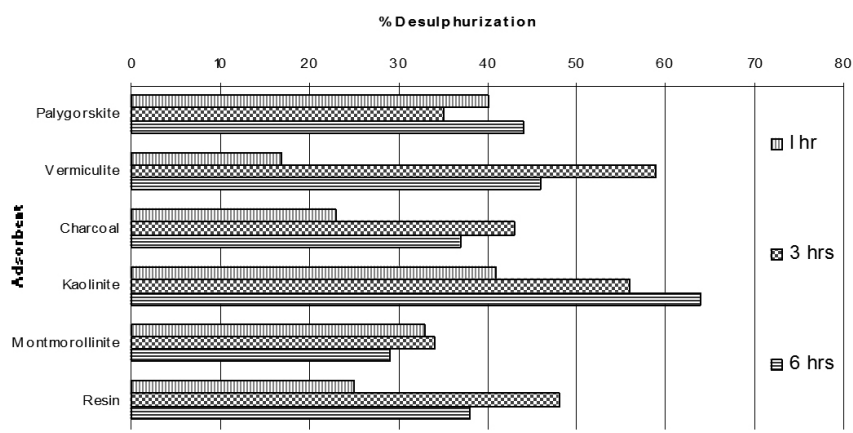

Fig.11.- \% Desulphurization of diesel by adsorption through different adsorbents at different time intervals. 


\subsection{FTIR Analysis:}

Jhal Magsi Crude oil: The FT-IR spectrum of the Jhal Magsi crude oil (virgin) is exhibited in Fig. 12-(a), show strong bands around 3000, 2925 and $2860 \mathrm{~cm}^{-1}$, which corresponds for aromatic $\mathrm{C}-\mathrm{H}$, methyl C-H and methylene $\mathrm{C}-\mathrm{H}$. The presence of mercaptans $\mathrm{S}-\mathrm{H}$ is indicated by a wide and strong band near $2350 \mathrm{~cm}^{-1}$. A low intensity absorption band at $1730 \mathrm{~cm}^{-1}$ indicates carbonyl $\mathrm{C}=\mathrm{O}$ bond, whereas a series of absorption bands ranging from 1500 to $1600 \mathrm{~cm}^{-1}$ corresponds for aromatic $\mathrm{C}=\mathrm{C}$. A strong band positioned at 1476 $\mathrm{cm}^{-1}$ represents the methylene $\mathrm{C}-\mathrm{C}$, followed by another intense band at 1374 $\mathrm{cm}^{-1}$ can be seen which corresponds to $\mathrm{S}=\mathrm{O}$ of sulphones. $\mathrm{S}-\mathrm{C}$ of sulphides is also indicated by a strong absorption band at $1166 \mathrm{~cm}^{-1}$. While a medium weak band given near $1029 \mathrm{~cm}^{-1}$ pertaining to $\mathrm{S}=\mathrm{O}$ bond of sulphoxides [26].

The spectrum of the crude oil adsorbed through kaolinite clay which shows the maximum desulphurization, is given in the Fig-12 (b) exhibit the presence of the band indicating aromatics, methyl, carbonyl $\mathrm{C}=\mathrm{O}$ and $\mathrm{C}=\mathrm{C}$ of aromatics or olefins, around 3000, 2950, 1730 and $1500-1600 \mathrm{~cm}^{-1}$, while the bands representing sulphur compounds like mercaptans (S-H), sulphoxides $(\mathrm{S}=\mathrm{O})$ and sulphides ( $\mathrm{R}-\mathrm{S}$ ) as well as carbonyl $\mathrm{C}=\mathrm{O}$, are totally missing, thus supporting the greater desulphurization activity of the clay.

Kerosene oil: The FT-IR spectrum of the virgin kerosene oil is shown in Fig-13(a) which indicates a broad band positioned at $3417 \mathrm{~cm}^{-1}$ corresponding to carboxylic acids O-H, strong absorption band at $2925 \mathrm{~cm}^{-1}$ showing methyl $\mathrm{C}-\mathrm{H}$, an intense band at $2830 \mathrm{~cm}^{-1}$ representing methylene $\mathrm{C}-\mathrm{H}$, and medium band at $2354 \mathrm{~cm}^{-1}$ for mercaptan $\mathrm{S}-\mathrm{H}$. Presence of carbonyl $\mathrm{C}=\mathrm{O}$ is indicated by and intense band at $1730 \mathrm{~cm}^{-1}$ and a consecutive weak bands ranging from 1500 to $1600 \mathrm{~cm}^{-1}$ show aromatic and aliphatic $\mathrm{C}=\mathrm{C}$. The spectrum of kerosene sample treated with kaolinite at 6 hrs, shows the common features of aliphatic and aromatics, while bands that evident the sulphur configurations as in virgin sample are not present, except that of for $\mathrm{S}=\mathrm{O}$ of sulphones.

Diesel oil: The FT-IR spectrum of the virgin diesel oil is given in Fig14(a) which shows the same pattern as in diesel. The spectrum exhibit the presence representative bands for carboxylic $\mathrm{O}-\mathrm{H}$ or amine $\mathrm{N}-\mathrm{H}$ at $3400 \mathrm{~cm}^{-1}$, aromatic C-H at $3100 \mathrm{~cm}^{-1}$, methyl C-H at $2930 \mathrm{~cm}^{-1}$, mercaptan S-H at 2356 $\mathrm{cm}^{-1}$. Besides, intense band at $1735 \mathrm{~cm}^{-1}$ represents carbonyl $\mathrm{C}=\mathrm{O}$ and a series of three medium to weak bands aromatic and aliphatic $\mathrm{C}=\mathrm{C}$ at $1500-1600$ $\mathrm{cm}^{-1}$. A medium band positioned at $1380 \mathrm{~cm}^{-1}$ corresponding for $\mathrm{S}=\mathrm{O}$ bond, show the presence of the sulphones. The evidence of the presence of sulphides is given by a weak band centered at $1204 \mathrm{~cm}^{-1}$ produced by sulphidic C-S bond. An intense band at $1043 \mathrm{~cm}^{-1}$ indicates the presence of the sulphoxides emerging due to the $\mathrm{S}-\mathrm{O}$ bonds. While the spectra of the sample desulphurized with Kaolinite clay show the characteristic bands for aromatic C-H, methyl and methylene $\mathrm{C}-\mathrm{H}$, olifinic $\mathrm{C}=\mathrm{C}$ and sulphones $\mathrm{S}=\mathrm{O}$, while no signatures for mercaptans, sulphoxides and sulphides are present.

The above discussion concludes that adsorption through Kaolinite clay has brought sufficient removal of sulphur compounds specially mercaptans and sulphides. Detailed peaks positions are given in Table-5 (a,b and c).

Table-5.- (a) Position and intensity of bands in the FTIR spectra of original and treated fractions (a) Crude oil (b) kerosene oil (c) diesel oil.

\begin{tabular}{llll}
\hline Sample & $\begin{array}{l}\text { Position } \\
\left(\mathbf{c m}^{-1}\right)\end{array}$ & $\begin{array}{l}\text { Intensity } \\
(\% \mathbf{r})\end{array}$ & $\begin{array}{l}\text { Assigned sulphur } \\
\text { configuration }\end{array}$ \\
\hline Jhal Magsi Crude (original) & 3000 & weak & $\mathrm{CH}$ (aromatic) \\
& 2930 & strong & $\mathrm{CH}_{3}$ (aliphatic) \\
& 2860 & strong & $\mathrm{CH}_{2}$ (aliphatic) \\
& 2350 & medium & $\mathrm{S}-\mathrm{H}$ (marcaptnes) \\
& 1730 & strong & $\mathrm{C}=\mathrm{O}$ (Ketone) \\
& $1500-1600$ & medium & $\mathrm{C}=\mathrm{C}$ (Aromatics) \\
& 1476 & weak & $\mathrm{C}-\mathrm{C}$ (methylene) \\
& 1374 & strong & $\mathrm{S}=\mathrm{O}$ (Sulphones) \\
1166 & strong & $\mathrm{S}-\mathrm{C}$ (Sulpide) \\
& 1029 & medium & $\mathrm{S}=\mathrm{O}$ (Sulphoxids) \\
Desulphurized with Kaolinite & 3000 & strong & $\mathrm{CH}$ (aromatic) \\
& 2950 & strong & $\mathrm{CH}$ (aliphatic) \\
& 1453 & medium & $\mathrm{C}=\mathrm{O}$ (Ketone) \\
$1500-1600$ & strong & $\mathrm{C}=\mathrm{C}$ (aromatics) \\
\hline
\end{tabular}

Table-5 (b). kerosene oil.

\begin{tabular}{clll}
\hline \multicolumn{1}{c}{ Sample } & $\begin{array}{l}\text { Position } \\
\left(\mathbf{c m}^{-1}\right)\end{array}$ & $\begin{array}{l}\text { Intensity } \\
(\% \mathbf{T})\end{array}$ & $\begin{array}{l}\text { Assigned sulphur } \\
\text { configuration }\end{array}$ \\
\hline Kerosene (original) & 3417 & broad & $\mathrm{OH}$ (carboxylic) \\
& 2925 & strong & $\mathrm{CH}_{3}$ (aliphatic) \\
& 2830 & strong & $\mathrm{CH}_{2}$ (aliphatic) \\
& 2354 & medium & $\mathrm{S}-\mathrm{H}$ (marcaptnes) \\
& 1730 & strong & $\mathrm{C}=\mathrm{O}$ (Ketone) \\
Desulphurized with Kaolinite & $1500-1600$ & medium & $\mathrm{C}=\mathrm{C}$ (Aromatics) \\
& 2930 & strong & $\mathrm{CH}_{3}$ (aliphatic) \\
& 2840 & strong & $\mathrm{CH}_{2}$ (aliphatic) \\
& 1735 & strong & $\mathrm{C}=\mathrm{O}$ (Ketone) \\
& $1500-1600$ & medium & $\mathrm{C}=\mathrm{C}$ (Aromatics) \\
\hline
\end{tabular}

Table-5 (c). Diesel Oil.

\begin{tabular}{clll}
\hline \multicolumn{1}{c}{ Sample } & $\begin{array}{l}\text { Position } \\
\left(\mathbf{c m}^{-1}\right)\end{array}$ & $\begin{array}{l}\text { Intensity } \\
(\% \mathbf{T})\end{array}$ & $\begin{array}{l}\text { Assigned sulphur } \\
\text { configuration }\end{array}$ \\
\hline 3420 & broad & $\mathrm{OH}$ (carboxylic) or NH (amines) \\
Kerosene (original) & strong & $\mathrm{CH}$ (aromatic) \\
2930 & strong & $\mathrm{CH}_{3}$ (aliphatic) \\
2860 & strong & $\mathrm{CH}_{2}$ (aliphatic) \\
2356 & medium & $\mathrm{S}-\mathrm{H}$ (marcaptnes) \\
1735 & strong & $\mathrm{C}=\mathrm{O}$ (Ketone) \\
$1500-1600$ & medium & $\mathrm{C}=\mathrm{C}$ (Aromatics) \\
1380 & medium & $\mathrm{S}=\mathrm{O}$ (Sulphones) \\
1204 & strong & $\mathrm{S}-\mathrm{C}$ (Sulphide) \\
1043 & medium & $\mathrm{S}=\mathrm{O}$ (Sulphoxids) \\
Desulphurized with Kaolinite & 2940 & strong & $\mathrm{CH}$ (aliphatic) \\
& 2855 & strong & $\mathrm{CH}$ (aliphatic) \\
& 1730 & strong & $\mathrm{C}=\mathrm{O}$ (Ketone) \\
$1500-1600$ & medium & $\mathrm{C}=\mathrm{C}$ (Aromatics) \\
1372 & strong & $\mathrm{S}=\mathrm{O}$ (Sulphones) \\
\hline
\end{tabular}

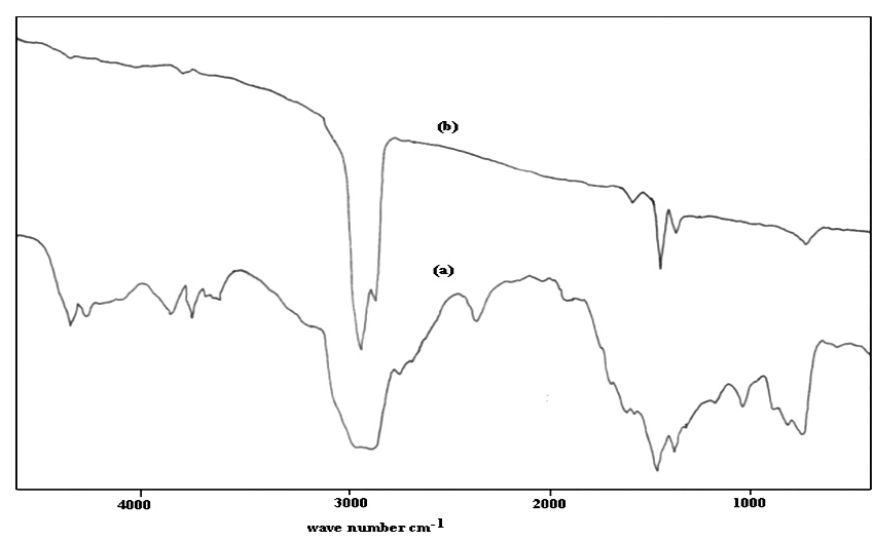

Fig. 12.- FT-IR spectra of the virgin and treated Jhal Magsi crude oil adsorbed through kaolinite clay (a) virgin sample (b) treated sample. 


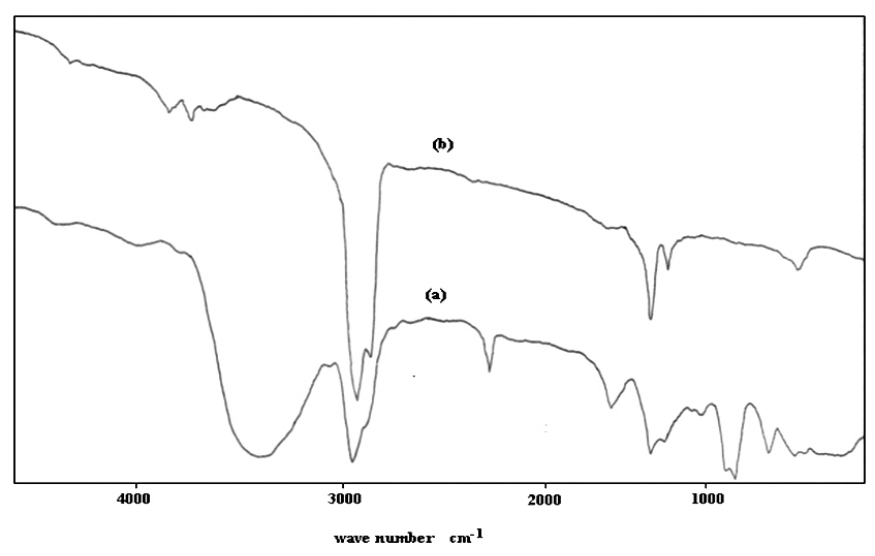

Fig.13..- FT-IR spectra of the virgin and treated diesel oil adsorbed through kaolinite clay (a) virgin sample (b) treated sample.

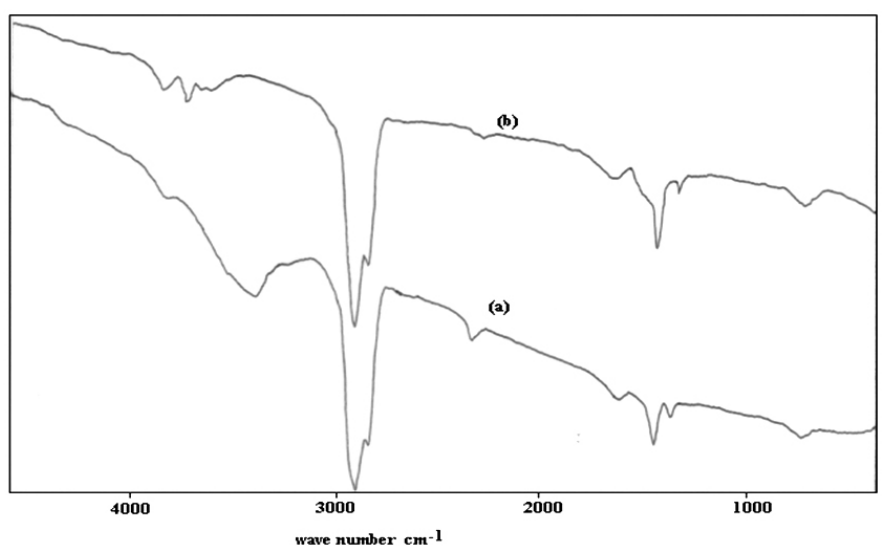

Fig.14.- FT-IR spectra of the virgin and treated kerosene oil adsorbed through kaolinite clay (a) virgin sample (b) treated sample.

\section{REFERENCE}

1. Y. Shiraishi, T. Hirai, I. Komasawa, Ind Eng Chem Res. 37, 203, (1998)

2. C. Song, Catal. Today. 77, 17, . (2002).

3. J. J. McKetta, Petroleum Processing Handbook, Marcel Dekker Inc. New York, (1992)

4. F. A. Mohammad, A. Abdullah, E. A. Bassam, Fuel. 85, 1354, (2006)

5. G. Mohebali, B. S. Andrew, Microbiology . 154, 2169, (2008)

6. M. Soleimani, A. Bassi, A. Margaritis, Biotechnol. Adv. 25, 570, (2007)

7. M. Shakirullah, I. Ahmad, I. M. Ishaq, W. Ahmad, J. Chin. Chem. Soc. 56, 107, (2009)

8. Y. Shiraishi, Y. Taki, T. Hirai, I. Komasawa, Ind. Eng. Chem. Res. 40, 1213, (2001)

9. A. M. Dehkordi, M. A. Sobati, M. A. Nazem, Chin. J Chem. Eng. 17, 869 , (2009)

10. K. Yazu, M. Makino, K. Ukegawa, Chem Lett. 33, 1306, (2004)

11. S. H. Ali, D. M. Hamad, B. H. Albusairi, M. A. Fahim, Energy Fuels. 23, 5986, (2009)

12. K. Tang, L. Song, L. Duan, X. Li, J. Gui, Z. Sun, Fuel Proc. Technol. 89, $1,(2008)$

13. J. C. Zhang, L. F. Song, J. Y. Hu, S. L. Ong, Y. H. Wang, J. G. Zhao, R. Y. Ma, Energy Convers. Manage. 46, 1, (2005)

14. M. Seredych, T. J. Bandosz, Energy Fuels. 24, 3352, (2010)

15. T. Fuping, L. Can, J. Zonxuan, L. Ying, Chin. J Catal. 26, 628, (2005)

16. S. G. Mckinley, R. J. Angelici, Chem. Commun. 20, 2620, (2003)

17. W. Mingels, E. M. Enody, E. F. Vansant, Eur. Pat. Appl. 275855. (1988)

18. A. B. S. H. Salem, In. Eng. Chem. Res. 33, 336, (1994)

19. A. B. S. H. Salem, H. S. Hamid, Chem. Eng. Technol. 20, 342, (1997)

20. J. Wetikamp, M. Scwarck, S. Ernst, J. Chem. Soc. Chem. Comm. 16, 1133, (1991)

21. S. Velu, M. Xiaoliang, S. Chunshan, Ind. Eng. Chem. Res. 42, 5293, (2003)
22. M. Hernandez, T. Y. Ralph, Ind. Eng. Chem. Res. 42, 123, (2003)

23. S. Mikhail, T. Zakia, L. Khalilb, Appl. Catal. A: General. 227, 265, (2002)

24. N. Hezil, K. Guerfi, S. Hazourli, A. Hammadi, S. Zeroual. Int. Sci. J. Altern. Ener. Ecol. 6, 169, (2008)

25. X. Yin, J. D. Miller, Miner. Metall. Process. 29, 13, (2012)

26. M. Shakirullah, W. Ahmad, I. Ahmad, M. Ishaq, Fuel Proc. Technol. 91, 1736, (2010). 